\title{
Predictive Value of Tumor Infiltrating Lymphocytes in Neoadjuvant Chemotherapy Treated Breast Cancer: A Meta-Analysis of 8052 Patients
}

Shiqi Li

Shenyang Pharmaceutical University

Ying Zhang

Shenyang Pharmaceutical University

Shujun Wang ( $\nabla$ 101030124@syphu.edu.cn)

Shenyang Pharmaceutical University https://orcid.org/0000-0002-1763-5147

Rui Yang

Liaoning University of Traditional Chinese Medicine

Research article

Keywords: Breast cancer, Tumor infiltrating lymphocytes, Neoadjuvant Chemotherapy, Prognosis, Meta-Analysis

Posted Date: October 8th, 2020

DOl: https://doi.org/10.21203/rs.3.rs-86621/v1

License: (9) (1) This work is licensed under a Creative Commons Attribution 4.0 International License. Read Full License 


\section{Abstract}

Background: We conducted a meta-analysis to determine the prognostic value of Tumor infiltrating lymphocytes (TILs) for patients with breast cancer on Neoadjuvant Chemotherapy, to explore the prognostic value of different TILs threshold in terms of pathological complete response (PCR).

Methods: A systematic search of PubMed, EMBASE and Web of Science electronic databases was conducted to identify eligible articles published before September 2020. Data from studies were analyzed by using Review Manager 5.3 and Stata 15.0

Results: A total of 22 published studies (including 8052 patients) were eligible. Patients with high TILs level showed a higher rate of PCR to treatment (OR=3.182, $95 \% \mathrm{Cl}, 2.549-3.973)$ compared to breast cancer patients with low TILs level. Although the association of TILs with response to neoadjuvant chemotherapy was similar across most breast cancer subtypes, there were a few differences ER negative or ER positive breast cancer. In studies (Type of breast cancer not clearly classified in the literature) where the cut-off value for TILs was $\geq 10 \%$, higher levels of total TILs predicted a higher PCR rate of Neoadjuvant Chemotherapy. However, for HER2-positive breast cancer patients, when a cut-off valve of TILs $\geq 30 \%$ was used, the OR was 2.631 ( $95 \%$ Cl, 1.739-3.982, $P=0.000)$. TILs also were related to better DFS (HR=0.95, $95 \% \mathrm{Cl}, 0.92-0.98, P=0.000)$ and overall survival $(\mathrm{OS})(\mathrm{HR}=0.90,95 \% \mathrm{Cl}, 0.85-0.95$, $P<0.0001)$ after Neoadjuvant Chemotherapy.

Conclusions: TILs can be used as predictors of patients with breast cancer on Neoadjuvant Chemotherapy. TILs threshold with the greatest prognostic significance of PCR is as yet unknown, but a TILs threshold of at least $30 \%$ is associated with the most powerful outcome prognostication of PCR.

\section{Introduction}

Breast cancer is one of the malignant tumors to threaten women's health around the world. In 2018, an estimated 2.1 million women were newly diagnosed with breast cancer in the world [1], 626,679 women with breast cancer died. Neoadjuvant chemotherapy (NACT) has been demonstrated to be of standard therapeutic strategy in locally advanced and inoperable breast cancer. It can convert a previous locally advanced and inoperable breast tumor into an operable tumor [2-3], and in largely operable tumors, downstaging results in a small increase (7\%-12\%) in breast conservation rates [4-6]. The MD Anderson Cancer Center and the International Breast Group defined unanimously Pathological complete response (PCR) as the complete disappearance of invasive cancer cells in primary breast tumor [7-8], studies have shown that PCR is an important predictor of prognosis for evaluating breast cancer patients with NACT. Patients who achieve PCR have favorable prognosis and longer survival period [9-11]. However, a small group of patients with NACT achieved PCR still relapse or die, whereas some patients without PCR have good prognosis. Thus, it is essential to find more biomarkers to evaluate the efficacy and prognosis of breast cancer patients for NACT.

Tumor infiltrating lymphocytes (TILs) are one of the significant components in tumor microenvironment, which reflect the intensity of the immune response within the tumor bed [12-14]. Studies have shown that TILs can predict a favorable outcome for neoadjuvant chemotherapy in breast cancer, but there is still controversy. A meta-analysis reported TILs cannot predict hormone receptor-negative breast cancer patients [15], but there were also reports of the opposite results [16]. High levels of specific phenotypes of TILs (CD8 ${ }^{+}$TIL, CD $4^{+}$TIL and Foxp $\left.3^{+}\right)$, were associated with a better prognosis of breast cancer patient after NACT [17-19], while a review shows a worse prognosis [15]. Studies have suggested [20-21] that compared with the lower density of intratumoral tumor infiltrating lymphocytes (iTIL), stromal Tumor infiltrating lymphocytes (sTIL) was the predominant location of TILs in breast cancer, which are most suitable as a biomarker. Even so, considering the International TILs Working Group recommendations, no formal recommendation for a clinically cut-off value of TILs was established up to now [22]. Previous researches agreed that cut-off value more than $50 \%$ TILs were defined as higher TILs, that is, lymphocyte predominant breast cancer (LPBC) [23]. However, it is still controversial to define the cut-off value of LPBC as $50 \%$ or $60 \%$ because of lower proportion of LPBC in clinical practice.

To address these controversies, we conducted a meta-analysis aimed to evaluate TILs, location or subtype of TILs as a potential prognostic marker for patients with breast cancer on Neoadjuvant Therapy, to explore the optimal thresholds and to determine the relationship between TILs and several clinicopathological features.

\section{Materials And Methods Literature search}

Eligible studies were identified by a systematic literature search of the PubMed, EMBASE and Web of Science databases, with date restriction up to August 2020. The search strategy was carried out using the following keywords: 'breast cancer', 'tumor infiltrating lymphocytes', 'tumor associated lymphocytes', 'CD3positiveT-lymphocytes', 'CD4-positiveT-lymphocytes', 'CD8-positiveT-lymphocytes', 'Foxp3-positiveT-lymphocytes' and 'neoadjuvant'. Independently searched by two authors (Li and Zhang), and any discrepancies were solved by discussion with a third author (Yang).

\section{Inclusion and exclusion criteria}

The studies included in the meta-analysis were either randomized controlled studies (RCTs) or case-control studies that evaluated the association between TILs and NACT for breast cancer. The inclusion criteria were as follows: (a) Study population or study subgroup consisted of breast cancer patient for NACT. (b) Investigated the predictive value for short-term prognosis or long-term prognosis of TILs and its subtypes $\mathrm{CD} 3^{+}, \mathrm{CD} 4^{+}, \mathrm{CD} 8^{+}, \mathrm{CXCL} 13$ and Foxp $3^{+}$ lymphocytes. (c) TILs were clearly defined, of which cut-off value chooses greater or equal to $10 \%$. (d) The published data contains articles with relative risk $(\mathrm{RR})$, odds ratio (OR) or hazard ratio (HR) and $95 \%$ confidence interval $(95 \% \mathrm{Cl})$. (e) Original research articles published in English with full-text. 
The exclusion criteria were following: (a) TILs were not clearly defined with using the median, quartiles or various scores and related statistics. (b) Lacking of key information such as, odds ratio (OR), hazard ratio (HR), 95\% Cl and $P$ value. (c) Non-English language. (d) In vitro and animal study. (e) Reviews, commentaries, editorials, protocols, case reports, qualitative research, or letters.

\section{Data extraction}

Two authors (Li and Zhang) independently extracted the data to ensure the reliability of the data. Any disagreements are resolved by consensus, a third party (Yang) will intervene if necessary. All data and information were recorded in pre-designed tables. We extracted the following data for this review: first author's name, publication date and country, study design information, number of participants, neoadjuvant chemotherapy program, median follow-up time, breast cancer type, TILs types, cut-off value, clinicopathological characteristics, outcome indicators of long-term prognosis and short-term prognosis.

The cut-off value of TILs varied in different studies, and we used predefined cut-off value to distinguish high and low TIL subgroups. 'High' TILs were defined according to the cut-off $\geq 10 \%$. Pathological complete response (PCR), defined as the absence of all invasive disease cells and lymph node metastasis [24]. Overall survival (OS), defined as the from the date of breast cancer diagnosis to the time of with any events, disease-free survival (DFS), defined as the period from the start of treatment to the first recurrence, or to death without any reason [25]. TILs can also be classified as stromal (sTILs) or intraepithelial (iTILs) according to different locations. To avoid bias from studies contributing very long-term follow-up data compared with other studies, both OS and DFS rates were standardized.

\section{Assessment of study quality}

Two authors (Li and Zhang) independently evaluated the risk of bias in 11 RCTs using the Cochrane Collaboration's risk of bias assessment tool [26], including the following seven modules: random sequence generation; allocation concealment; blinding (participants, personnel, and outcome assessment); incomplete outcome data; and selective reporting and other bias. These domains are categorized as having a high, low, or unclear risk of bias. 11 qualified case-control studies were assessed according to the Newcastle-Ottawa scale (NOS) [27]. The NOS contains eight items, which are categorized into the three dimensions of selection, comparability, and exposure (case control studies). The quality scores in NOS ranged from 0 to 9 and studies with scores 6 or more are rated as high quality. If there is any disagreement in the results of the literature quality evaluation, it is resolved by consensus, and a third author (Yang) will intervene if necessary.

\section{Statistical analysis}

TILs were analyzed as continuous variable (per 10\% increment) and binary variable (cut-off value $\geq 10 \%$ ). For continuous variable, $\mathrm{HR}$ and $95 \% \mathrm{Cl}$ were calculated for the effect of TILs in terms of DFS, OS and PCR. For binary variable, we evaluated the overall OR and $95 \% \mathrm{Cl}$ of eligible data for the predictive value of TILs in PCR to NACT. An OR $>1$ indicates higher PCR in breast cancer patients with higher TILs group, an OR $<1$ indicates lower PCR in breast cancer patients with higher TILs group. HR $<1$ indicates that TILs can predict DFS and OS in breast cancer patients with NACT, HR $>1$ is the opposite. The pooled OR and $\mathrm{HR}$ are considered statistically significant if the $95 \% \mathrm{Cl}$ did not include 1.0 , with a $P$ value of $\leq 0.05$.

The Mantel-Haenzel method was used to obtain fixed effects model of the pooled ORs [28], and standard checks of the homogeneity assumption were performed [29]. In the presence of significant heterogeneity among the trials, estimate the ORs using the random effects model [30], and use sensitivity analyses. To obtain a quantitative measure of the degree of inconsistency in the results of the studies, the Higgins $P$ index was computed [31]. The likelihood of publication bias was assessed by visual inspection of funnel plot for study size against treatment effect [32]. The STATA software version 15.0 or Revman5.3 were used for all statistical analyses.

\section{Results}

\section{Search results and characteristics of eligible studies}

The systematic literature search returned 885 records (Fig. 1). Finally, 11 potentially eligible RCTs [33-42, 54] and 11 case-control studies [43-53] were considered, consisting of approximately 8052 participants. The population of patients in each study varied from 50 to 1060 cases, and the follow-up time ranged from 3.4 to 120 months. Six and 12 publications had available data for the OS and DFS analyses respectively. Nineteen studies provided evidence of the prognostic value of TILs for PCR. Cut-off chosen were 10\% ( $n=2) ; 30 \%(n=2) ; 40 \%(n=1) ; 50 \%(n=3) ; 60 \%(n=7) ; 70 \%(n=1)$. The continuous variable most used per $10 \%$ increment. The majority of NACT regimen contains anthracycline and taxane. Trastuzumab or lapatinib were typically used in HER2positive patients. The basic characteristics and target outcomes extracted from the included studies are listed in Table 1.

\section{Literature quality evaluation results}

We evaluated the risk of bias for all included prospective studies $(n=11)$. The main sources of bias were related to blinded (participants and personnel). The risk of bias assessments for each cohort and evaluations for each domain across full reported studies are shown in Supplementary Fig. 1a and Fig. 1b.

\section{Correlation of TILs with clinicopathological parameters}

The correlations between clinicopathologic characteristics and TILs were analyzed in Table 2. Total TILs levels were not associated with tumor grade, tumor size and patients age, but there was association with shorter DFS in node-positive breast cancer patients (pooled $\mathrm{HR}=3.340,95 \% \mathrm{Cl}, 2.280-4.890$ ).

Unfortunately, we had not analyzed the relationship of Ki-67, hormone receptor or HER2 status due to the limited data.

TILs and PCR 
The 17 studies were eligible to be assessed for TILs and PCR. For binary variable, high level of TILs was correlated with better PCR rate, pooled OR = 3.182, $95 \% \mathrm{Cl}, 2.549-3.973, P=0.000$, and no significant heterogeneity (Fig. 2a). In a subgroup analysis of different types of breast cancer, for HER2- positive breast cancer (pooled OR = 2.329, 95\% Cl, 1.174-4.621, $P=0.016$ ), HER2-negative breast cancer (pooled OR $=3.386,95 \% \mathrm{Cl}, 2.242-5.115, P=0.000$ ) and TNBC (pooled OR = 7.571, 95\% Cl, 3.631-15.784, $P=0.000$ ), higher total TILs level was correlated with better PCR (Fig. 2b, Fig. 2c and Fig. 2d), but not for ER negative and ER positive breast cancer (Fig. 2e and Fig. 2f ).

In a subgroup analysis, high level of TILs subtypes, CD8 ${ }^{+}$TILs (polled OR $\left.=3.300,95 \% \mathrm{Cl}, 1.730-6.294, P=0.000\right)$ and Foxp3 ${ }^{+} \mathrm{TILs}(\mathrm{polled} \mathrm{OR}=2.353,95 \% \mathrm{Cl}$, 1.273-4.347, $P=0.006$ ) also predicted better pathological response to NACT. For HER2-positive patients received trastuzumab or lapatinib, meta- analysis showed that high levels of TILs may not enhance the efficacy of an anti-HER2 therapy by trastuzumab (pooled OR $=0.670,95 \% \mathrm{Cl}, 0.081-5.504, P=0.709)$ and lapatinib (pooled $\mathrm{OR}=1.307,95 \% \mathrm{Cl}, 0.123-13.878, P=0.824$ ).

\section{Cut-off value of TILs and PCR}

We used predefined cut-off points to distinguish high and low TIL subgroups. In studies (types of breast cancer not clearly classified in the literature) and where the cut-off value for TILs was $\geq 10 \%$, the high level of TILs can predict PCR rate better. This cut-off value of TILs applied to the TNBC patients, either. However, for HER2-positive breast cancer patients, subgroup analysis showed in 2 studies where the cut-off value for TILs was $10 \%$, the pooled OR for PCR was $0.683(95 \% \mathrm{Cl}, 0.029-16.014, P=0.813)$. If we grouped studies with a cut-off of TILs $\geq 30 \%$, the OR was $2.631(95 \% \mathrm{Cl}, 1.739-3.982, P=0.000)$ and $\mathrm{no}$ significant heterogeneity $(P=0.104, P=45.2 \%)$.

\section{TILs and DFS}

A total of 8 studies were eligible to be assessed for TILs and DFS. When TIL level was assessed as a continuous variable (per 10\% increase), patients with increased TIL level in breast cancer had significantly longer DFS than did patients with lower TIL levels (pooled $\mathrm{HR}=0.95,95 \% \mathrm{Cl}, 0.92-0.98, P=0.0003$ ) (Fig. 3a). The pooled data suggested both iTILs (pooled HR $=0.91,95 \% \mathrm{Cl}, 0.84-0.98, P=0.020$ ) and sTILs (pooled HR $=0.96,95 \% \mathrm{Cl}, 0.93-0.98, P=0.003$ ) were associated with better DFS.

In the HER2-positive patients (pooled HR=0.96, 95\% Cl, 0.94-0.97, $P<0.00001$ ) and TNBC patients (pooled HR=0.85, 95\%Cl, 0.78-0.92, $P<0.0001$ ), TILs were significantly associated with better DFS (Fig. 3b and Fig. 3c). The association between TILs and survival was similar between iTILs and sTILs. Subgroup analyses according to TILs subtypes, Both CD8 ${ }^{+}$(polled HR 1.00, 95\% Cl 1.00-1.00) and CXCL13 (polled HR 0.55, 95\% Cl 0.38-0.78) predicted better for DFS after NACT. On the contrary, the meta-analysis confirmed that for any $10 \%$ increase of FOXP3 ${ }^{+}$level there was a poor DFS (polled HR $1.11,95 \%$ CI $0.76-1.62$ ).

\section{TILs and OS}

We assessed TILs as a prognostic marker for OS from 6 studies. Meta-analysis results showed that breast cancer patients with high level of TILs showed a favorable OS after NACT (pooled HR $=0.90,95 \% \mathrm{Cl}, 0.85-0.95, P<0.0001$ ) (Fig. 4a). Both iTILs (pooled HR $=0.86,95 \% \mathrm{Cl}, 0.75-0.99, P=0.030$ ) and sTILs (pooled $\mathrm{HR}=0.91,95 \% \mathrm{Cl}, 0.86-0.96, P=0.0006$ ) achieved similar results. In a subgroup analysis of types of breast cancer, a $10 \%$ increase in TILs was associated with longer OS in HER2-positive breast cancer (pooled $\mathrm{HR}=0.93,95 \% \mathrm{Cl}, 0.87-0.99, P=0.010)$ and TNBC (pooled $\mathrm{HR}=0.86,95 \% \mathrm{Cl}, 0.79-0.93, P=$ 0.0003) (Fig. 4b and Fig. 4c).

\section{Publication bias}

Funnel plot analysis which was performed to assess the publication bias of the selected studies for the pooled PCR rate (Supplementary Fig. 2). Visual inspection of analysis indicated some evidence of asymmetry, but Egger's tests indicated that there was no significant publication bias, $P>0.5$. Limited data for OS outcome indicators, so we did not do the funnel plot.

\section{Sensitivity analysis}

To assess the impact of each included study, a sensitivity analysis was performed. After excluding each study, similar results were observed.

\section{Discussion}

It is well known that TILs of tumor microenvironment modulate the cancer cell killing effect of NACT. TILs can not only effectively reflect the interaction between the immune microenvironment of the body and tumor cells, but also predict the outcome and treatment effect from the side, so as to make certain guidance for the formulation and adjustment of clinical treatment plan for tumor patients. However, concerning the effect of TILs on NACT treatment outcome in breast tumors, the results are sometimes discordant. Obviously, this meta-analysis is the first study to evaluate systematically the relationship between TILs, a new biomarker for breast cancer, and the outcome of NACT.

\section{Correlation of TILs with clinicopathological parameters}

We analyzed the relationship between TILs and clinicopathological characteristics. As reported in most literature, total TILs are not associated with age or tumor size in breast cancer patients $[33,35,39,43,50]$. Earlier published showed that there was major correlation between the expression of TILs and lymph node status $[49,52]$, which was similar with our research. TILs highly expressed in axillary lymph node status positive breast cancer patients, has a high risk of recurrence and metastasis. Denkert C [41] showed that TIL levels of breast cancer differed by tumor grade, but our study did not achieve a similar result. Therefore, it would be significative to further explore the relationships between clinicopathologic characteristics and TILs.

\section{Impact of TILs on PCR prognosis}


In clinical application, PCR has always been regarded as an indicator of the short-term prognosis of NACT. In recent years, the impact of TILs on the PCR rate for patients with breast cancer on Neoadjuvant Therapy, has attracted much attention. We observed a consistent positive association of increased TILs level with increased PCR, especially in HER2-positive breast cancer and TNBC [21], two molecular subtypes that have obvious response to NACT treatment. Several literature reports $[21,54]$ that the effect of TILs for PCR had the opposite effect in HER2-negative breast cancer, compared with TNBC and HER2-positive breast cancer. By contrast, our meta-analysis showed TILs to be a prognostic marker that can also better predict PCR for HER2-negative breast cancer patients receiving NACT. However, due to the limited literature included in this study, careful analysis is needed. Patients with high-level TILs were confirmed to have a higher chance of achieving PCR, but there were a few differences in Estrogen Receptor (ER) subtypes. We found the high-level TILs not correlated with higher PCR rate in ER negative or ER positive breast cancer, which is slightly different from the previous reports [15-16]. In summary, the predictive value of TILs levels on NACT response is different in all molecular subtypes. This supports the hypothesis that the cellular composition of immune infiltration in tumors is different among each breast cancer type, which determines different clinical outcomes and NACT response [55].

Patients confirmed to have HER2 amplification further receive weekly trastuzumab or lapatinib infusions. For HER2-positive patients received trastuzumab, the prognostic role of TILs has not been definitely ascertained. A study reports [37] that high levels of TILs may further enhance the efficacy of an anti-HER2 therapy by trastuzumab compared with lapatinib therapy. However, our analysis showed that high levels of TILs may not enhance the efficacy of an anti-HER2 therapy by trastuzumab and lapatinib, and cannot predict the PCR prognostic effect of these drugs. Further studies should be conducted to determine whether HER2-positive patients with higher TILs level can obtain benefit from trastuzumab and lapatinib therapy, due to limited data.

\section{Cut-off value of TILs and PCR}

In our meta-analysis, we used predefined cut-off value to distinguish high and low groups with different TIL levels, but the actual distribution of TILs suggests that these were artificial cut-off. The number of TILs was a continuous variable, which could reach any proportion (0-100\%). Nevertheless, the categorization into low and high levels of TILs might be relevant for future clinical applications, since stratification in clinical trials can be more easily done on the basis of categorical variables that divide patients into different groups.

The TILs threshold with the greatest prognostic significance is as yet unknown. Our result showed when a cut-off value of TILs $\geq 10 \%$ was used, high levels of TILs predict a better PCR rate of NACT. However, for HER2-positive breast cancer, a cut-off $\geq 30 \%$ is associated with a greater rate of PCR compared with lower expression levels. In order to determine the optimal threshold of TILs in future clinical trials and improve the accuracy of pathological assessment and prognosis prediction, a TILs threshold of at least $30 \%$ is associated with the most powerful outcome prognostication of PCR.

\section{Impact of TILs on long-term prognosis}

In general, DFS and OS have been regarded as long-term prognostic indicators of NACT. Previous studies [15-16] had shown that higher level of TILs suggested a better prognosis of patients with breast cancer on Neoadjuvant Therapy. Our study also indicated per 10\% increase TILs means an extension of DFS and OS, specifically in patients belonging to TNBC groups. One possible explanation of the differences between HER2 breast cancer and TNBC could be the contribution of different immune cell types. TNBC are considered subtypes with high immunoreactivity. In TNBC, the presence of many immune cell subtypes, including B cells, T cells, and macrophages, were linked to improved survival. Unfortunately, data from the HER2-negative breast cancer was not enough available for TIL analysis.

In actual clinical, the number of iTILs were correlated with the number of sTILs, but typically had a much lower density and therefore were less suitable as a biomarker. But our meta-analysis showed that value of TILs for prognostic implication was not affected by TILs location, both iTILs and sTILs contributed to better prognosis and favorable survival.

\section{Prognostic value of TILs subtypes}

It is worth noting that TILs contain a variety of subgroups, reflecting that lymphocytes in tumor microenvironment can affect the balance of immune response, leading to different outcomes. Some studies reported that Foxp $3^{+}$TILs can suppress antitumor immune response and lead to escape immune clearance [5658]. Therefore, patients with high expression levels of Foxp $3^{+}$TILs have few chances of obtaining survival benefit from NACT. On the contrary, recruitment of activated $\mathrm{CD}^{+}$cytotoxic $\mathrm{T}$ cell of NACT is associated with a better outcome [59-60]. However, our meta-analysis results showed the higher PCR rate of breast cancer patients with high expression levels of Foxp ${ }^{+}$TILs or CD8 ${ }^{+}$TILs, but significant association between FOXP3 ${ }^{+}$TILs and DFS were not observed.

Besides, an increasing body of evidence suggested that humoral immunity, is important too. CXCL13, formerly termed B cell-attracting chemokine 1 , is a cytokine that belongs to the CXC chemokine family. Previously, the expression of immune-related genes in pre-NACT biopsies obtained from TNBC patients was investigated and the expression of the CXCL13 mRNA transcripts. Therefore, CXCL13 also was a predictor of PCR [61]. Gu-Trantien [62] reported that the infiltration of CXCL13-producing CD4 $4^{+}$follicular helper T cells and a CXCL13 gene expression signature were related to a longer disease-free survival in breast cancer patients. Similarly, our pooled analysis results showed CXCL13 gene expression characteristics can prolong the disease-free survival time of breast cancer patients.

\section{Limitations}

In spite of this, there still exist some limitations in this meta-analysis. Some of individual results had large heterogeneity, which may be related to differences in the age and types of breast cancer, as well as clinical research methodology included in the study. This study only included published literature in English and limited quantity literature, there might exist language bias and study heterogeneity. Besides, some of the studies we included are retrospective studies, correctness of the results depended on the accuracy of the original literature research, we therefore formulated the strict inclusion and exclusion standard. 


\section{Conclusions}

In conclusion, our findings indicate that total TILs can be used as predictors of patients with breast cancer on Neoadjuvant Therapy. The higher the infiltration degree of TILs predicted the better prognosis of neoadjuvant chemotherapy, except for ER-negative and ER-positive breast cancer subtypes. Notably, some subtypes like Foxp $3^{+}$TILs show a worse long-term prognosis.

A TILs threshold of at least $30 \%$ is associated with the most powerful outcome prognostication of PCR. However, a large number of prospective trials are still needed.

\section{Abbreviations}

TILs: Tumor-infiltrating lymphocytes; PCR: Pathological complete response; DFS: Disease-free survival; OS: Overall survival; Cl: Confidence intervals; OR: Odds ratio; HR: Hazard ratios; RR: relative risk; ER: Estrogen receptor; NACT: Neoadjuvant chemotherapy; LPBC: lymphocyte predominant breast cancer; RCTs: randomized controlled studies; sTIL: stromal Tumor infiltrating lymphocytes; iTIL: intratumoral tumor infiltrating lymphocytes; NOS: Newcastle-Ottawa scale; HER2: Human epidermal growth factor receptor 2; TNBC: Triple-negative breast cancer.

\section{Declarations}

\section{Acknowledgements}

The authors are pleased to acknowledge the suggestions from Professor Shujun Wang, which is important for manuscript revision.

\section{Funding}

This study was supported by the project information of the Academy of Military Sciences: BWS16J007 national key project, the military commission logistics support department applied basic research key project.

\section{Authors' contributions}

$\mathrm{Li}$ carried out the initial background research and drafted the manuscript. Li, Yang and Zhang acted as independent reviewers in screening literature, extracting data, and assessing the quality of each study. Li, Zhang, Yang and Wang helped in developing the manuscript or revising it critically for important intellectual content. The author(s) read and approved the final manuscript.

\section{Competing interests}

We have no conflicts of interest with any other authors.

\section{Availability of data and materials}

Not applicable.

\section{Ethics approval and consent to participate}

Not applicable

\section{Consent for publication}

Not applicable.

\section{References}

1. Bray F, Ferlay J, Soerjomataram I, et al. Global cancer statistics 2018: GLOBOCAN estimates of incidence and mortality worldwide for 36 cancers in 185 countries. CA Cancer J Clin. 2020 Jul;70(4):313. CA Cancer J Clin. 2018;68(6):394-424. doi:10.3322/caac.21492.

2. Wang H, Mao X. Evaluation of the Efficacy of Neoadjuvant Chemotherapy for Breast Cancer. Drug Des Devel Ther. 2020; 14:24232433.doi:10.2147/DDDT.S253961

3. Costa SD, Loibl S, Kaufmann M. Neoadjuvant chemotherapy shows similar response in patients with inflammatory or locally advanced breast cancer when compared with operable breast cancer:a secondary analysis of the GeparTrio trial data. J Clin Oncol.2010;28(1):83-91. doi:10.1200/JCO.2009.23.5101

4. Katz SJ. Surgeon recommendations and receipt of mastectomy for treatment of breast cancer. Obstet Gynecol Surv. 2009;65 (14):1551-1556.

5. Buchholz TA, Mittendorf EA, Hunt KK. Surgical considerations after neoadjuvant chemotherapy: breast conservation therapy. J Natl Cancer Inst Monogr. 2015;51:51.

6. Schott AF, Hayes DF. Defining the benefits of neoadjuvant chemotherapy for breast cancer. J Clin Oncol. 2012;30(15):17471749.doi:10.1200/JC0.2011.41.3161.doi:10.1016/S0140-6736(13)62422-8.

7. Laura Spring, Rachel Greenup, Kerry Reynolds, et al. Abstract 1439: Pathological complete response after neoadjuvant chemotherapy predicts improved survival in all major subtypes of breast cancer: systematic review and meta-analyses of over 18,000 patients[J]. 2016. doi:10.1158/1538-7445.AM2016- 
1439.

8. Bear HD, Anderson S, Smith RE, et al. Sequential preoperative or postoperative docetaxel added to preoperative doxorubicin plus cyclophosphamide for operable breast cancer: National Surgical Adjuvant Breast and Bowel Project Protocol B-27. J Clin Oncol. 2006;24(13):2019-2027. doi:10.1200/JC0.2005.04.1665.

9. Spring LM, Fell G, Arfe A, et al. Pathologic Complete Response after Neoadjuvant Chemotherapy and Impact on Breast Cancer Recurrence and Survival: A Comprehensive Meta-analysis. Clin Cancer Res. 2020;26(12):2838-2848. doi:10.1158/1078-0432.CCR-19-3492

10. Cortazar P, Zhang L, Untch M, et al. Pathological complete response and long-term clinical benefit in breast cancer: the CTNeoBC pooled analysis.Lancet 2014;384:164-72. doi:10.1016/S0140-6736(13)62422-8.

11. Laura Spring, Rachel Greenup, Kerry Reynolds, et al. Abstract 1439: Pathological complete response after neoadjuvant chemotherapy predicts improved survival in all major subtypes of breast cancer: systematic review and meta-analyses of over 18,000 patients[J]. 2016.doi:10.1158/1538-7445.AM20161439.

12. Deshmukh SK, Srivastava SK, Poosarla T, et al. Inflammation, immunosup-pressive microenvironment and breast cancer: opportunities for cancer prevention and therapy. Ann Transl Med. 2019;7(20):593. doi:10.21037/atm.2019.09.68.

13. Mittal S, Brown NJ, Holen I. The breast tumor microenvironment: role in cancer development, progression and response to therapy. Expert Rev Mol Diagn 2018;18:227-43.doi:10.1080/14737159.2018.1439382.

14. Soysal SD, Tzankov A, Muenst SE. Role of the T umor Microenvironment in Breast Cancer. Pathobiology 2015;82:142-152. doi:10.1159/000430499.

15. Yu X, Zhang Z, Wang Z, et al. Prognostic and predictive value of tumor-infiltrating lymphocytes in breast cancer: a systematic review and meta-analysis. Clin TransI Oncol. 2016;18(5):497-506. doi:10.1007/s12094-015-1391-y.

16. Mao Y, Qu Q, Zhang Y, et al. The value of tumor infiltrating lymphocytes (TILs) for predicting response to neoadjuvant chemotherapy in breast cancer: a systematic review and meta-analysis PLoS One. 2015;10(3). doi:10.1371/journal.pone.0115103.

17. Matsumoto H, Thike AA, Li H, et al. Increased CD4 and CD8-positive T cell infiltrate signifies good prognosis in a subset of triple-negative breast cancer[J]. Breast Cancer Res Treat, 2016, 156(2): 237-247. doi:10.1007/s10549-016-3743-x.

18. De Groot AF, Blok EJ, Charehbili A, et al. Strong CD8+ lymphocyte infiltration in combination with expression of HLA class I is associated with better tumor control in breast cancer patients treated with neoadjuvant chemotherapy. Breast Cancer Res Treat. 2019;175(3):605-615. doi:10.1007/s10549-019-05195y.

19. Solinas C, Carbognin L, De Silva P, et al. Tumor-infiltrating lymphocytes in breast cancer according to tumor subtype: Current state of the art. Breast. 2017;35:142-150. doi:10.1016/j.breast.2017.07.005.

20. Carbognin L, Pilotto S, Nortilli R, et al. Predictive and Prognostic Role of Tumor-Infiltrating Lymphocytes for Early Breast Cancer According to Disease Subtypes: Sensitivity Analysis of Randomized Trials in Adjuvant and Neoadjuvant Setting. Oncologist. 2016;21(3):283-291. doi:10.1634/theoncologist.2015-0307.

21. Denkert C, von Minckwitz G, Darb-Esfahani S, et al. Tumour-infiltrating lymphocytes and prognosis in different subtypes of breast cancer: a pooled analysis of 3771 patients treated with neoadjuvant therapy. Lancet Oncol. 2018;19(1):40-50. doi:10.1016/S1470-2045(17)30904-X.

22. Salgado R, Denkert C, Demaria S, et al. The evaluation of tumor-infiltrating lymphocytes (TILs) in breast cancer: recommendations by an international TILs working group 2014. Ann Oncol. 2015;26(2):259-71. doi:10.1093/annonc/mdu450.

23. Jung YY, Hyun CL, Jin MS, et al. Histomorphological Factors Predicting the Response to Neoadjuvant Chemotherapy in Triple-Negative Breast Cancer. J Breast Cancer. 2016;19(3):261-267. doi:10.4048/jbc.2016.19.3.261.

24. Fisher B, Bryant J, Wolmark N, et al. Effect of preoperative chemotherapy on the outcome of women with operable breast cancer. $\mathrm{J}$ Clin Oncol. 1998;16:2672-2685. doi:10.1200/JC0.1998.16.8.2672.

25. Ovcaricek T, Frkovic S, Matos E, et al. Triple negative breast cancer prognostic factors and survival. Radiol Oncol. 2011;45:46-52. doi:10.2478/v10019010-0054-4.

26. Higgins JP, Altman DG, Gøtzsche PC, et al. The Cochrane Collaboration's tool for assessing risk of bias in randomised trials. BMJ. 2011;343:d5928. doi:10.1136/bmj.d5928.

27. Wells GA, Shea B, O'Connell D, et al. The Newcastle-Ottawa Scale (NOS) for assessing the quality of nonrandomised studies in meta-analyses. Ottawa, ON, Canada: Ottawa Hospital Research Institute; 2014. doi:10.1371/journal.pntd.0002195.

28. Mantel N, Haenszel W. Statistical aspects of the analysis of data from retrospective studies of disease. J Natl Cancer Inst 1959; 22 (4): 719-748.

29. Higgins J, Thompson S, Deeks J, et al.. Statistical heterogeneity in systematic reviews of clinical trials: a critical appraisal of guidelines and practice. J Health Serv Res Policy 2002; 7(1): 51-61. doi:10.1258/1355819021927674.

30. DerSimonian R, Laird N. Meta-analysis in clinical trials. Control Clin Trials. 1986; 7(3): 177-188. doi:10.1016/0197-2456(86)90046-2.

31. Higgins JPT, Thompson SG. Quantifying heterogeneity in a meta-analysis. Stat Med 2002; 21(11): 1539-1558. doi:10.1002/sim.1186.

32. Harbord RM, Egger M, Sterne JAC. A modified test for small-study effects in meta-analyses of controlled trials with binary endpoints. Stat Med 2006; 25(20): 3443-345. doi:10.1002/sim.2380.

33. Denkert C, Loibl S, Noske A, et al. Tumor-associated lymphocytes as an independent predictor of response to neoadjuvant chemotherapy in breast cancer [published correction appears in J Clin Oncol.2010Feb 1;28(4):708]. J Clin Oncol. 2010;28(1):105-113. doi:10.1200/JC0.2009.23.7370

34. Loi S, Michiels S, Salgado R, et al. Tumor infiltrating lymphocytes are prognostic in triple negative breast cancer and predictive for trastuzumab benefit in early breast cancer: results from the FinHER trial. Ann Oncol. 2014;25(8):1544-1550. doi:10.1093/annonc/mdu112 
35. Salgado R, Denkert C, Campbell C, et al. Tumor-Infiltrating Lymphocytes and Associations With Pathological Complete Response and Event-Free Survival in HER-2 Positive Early-Stage Breast Cancer Treated With Lapatinib and Trastuzumab: A Secondary Analysis of the NeoALTTO Trial. JAMA Oncol. 2015;1(4):448-454. doi:10.1001/jamaoncol.2015.0830.

36. Dieci MV, Prat A, Tagliafico E, et al. Integrated evaluation of PAM50 subtypes and immune modulation of PCR in HER2-positive breast cancer patients treated with chemothe-rapy and HER2-targeted agents in the CherLOB trial. Ann Oncol. 2016;27(10):1867-1873. doi:10.1093/annonc/mdw262.

37. Ingold Heppner B, Untch M, Denkert C, et al. Tumor-Infiltrating Lymphocytes: A Predictive and Prognostic Biomarker in Neoadjuvant-Treated HER2-Positive Breast Cancer. Clin Cancer Res. 2016;22(23):5747-5754. doi:10.1158/1078-0432.CCR-15-2338.

38. Loibl S, de la Pena L, Nekljudova V, et al. Neoadjuvant buparlisib plus trastuzumab and paclitaxel for women with HER2+ primary breast cancer: A randomised, double-blind, placebo-controlled phase II trial (NeoPHOEBE). Eur J Cancer. 2017;85:133-145. doi:10.1016/j.ejca.2017.08.020.

39. Ignatiadis M, Van den Eynden G, Roberto S, et al. Tumor-Infiltrating Lymphocytes in Patients Receiving Trastuzumab/Pertuzumab-Based Chemotherapy: A TRYPHAENA Substudy. J Natl Cancer Inst. 2019;111(1):69-77. doi:10.1093/jnci/djy076.

40. Schmidt M, Weyer-Elberich V, Hengstler JG, et al. Prognostic impact of CD4-positive T cell subsets in early breast cancer: a study based on the FinHer trial patient population. Breast Cancer Res. 2018;20(1):15. doi:10.1186/s13058-018-0942-x

41. Denkert C, von Minckwitz G, Brase JC, et al. Tumor-infiltrating lymphocytes and response to neoadjuvant chemotherapy with or without carboplatin in human epidermal growth factor receptor 2-positive and triple-negative primary breast cancers. J Clin Oncol. 2015;33(9):983-991. doi:10.1200/JC0.2014.58.1967

42. Würfel F, Erber R, Huebner H, et al. TILGen: A Program to Investigate Immune Targets in Breast Cancer Patients - First Results on the Influence of TumorInfiltrating Lymphocytes. Breast Care (Basel). 2018;13(1):8-14. doi:10.1159/000486949

43. Ochi T, Bianchini G, Ando M, et al. Predictive and prognostic value of stromal tumour-infiltrating lymphocytes before and after neoadjuvant therapy in triple negative and HER2-positive breast cancer. Eur J Cancer. 2019;118:41-48. doi:10.1016/j.ejca.2019.05.014.

44. Song IH, Heo SH, Bang WS, et al. Predictive Value of Tertiary Lymphoid Structures Assessed by High Endothelial Venule Counts in the Neoadjuvant Setting of Triple-Negative Breast Cancer. Cancer Res Treat. 2017;49(2):399-407. doi:10.4143/crt.2016.215

45. Cerbelli B, Pernazza A, Botticelli A, et al. PD-L1 Expression in TNBC: A Predictive Biomarker of Response to Neoadjuvant Chemotherapy?. Biomed Res Int. 2017;2017:1750925. doi:10.1155/2017/1750925.

46. Khoury T, Nagrale V, Opyrchal M, et al. Prognostic Significance of Stromal Versus Intratumoral Infiltrating Lymphocytes in Different Subtypes of Breast Cancer Treated With Cytotoxic Neoadjuvant Chemotherapy. Appl Immunohistochem Mol Morphol. 2018;26(8):523-532. doi:10.1097/PAl.0000000000000466

47. Asano Y, Kashiwagi S, Goto W, et al. Prediction of Treatment Response to Neoadjuvant Chemotherapy in Breast Cancer by Subtype Using Tumorinfiltrating Lymphocytes. Anticancer Res. 2018;38(4):2311-2321. doi:10.21873/anticanres.12476.

48. Russo L, Maltese A, Betancourt L, et al. Locally advanced breast cancer: Tumor-infiltrating lymphocytes as a predictive factor of response to neoadjuvant chemotherapy. Eur J Surg Oncol. 2019;45(6):963-968. doi:10.1016/j.ejso.2019.01.222.

49. Ruan M, Tian T, Rao J, et al. Predictive value of tumor-infiltrating lymphocytes to pathological complete response in neoadjuvant treated triple-negative breast cancers. Diagn Pathol. 2018;13(1):66. doi:10.1186/s13000-018-0743-7.

50. Yang X, Rao J, Yang W, et al. Evaluation of the Predictive and Prognostic Values of Stromal Tumor-Infiltrating Lymphocytes in HER2-Positive Breast Cancers treated with neoadjuvant chemotherapy. Target Oncol. 2018;13(6):757-767. doi:10.1007/s11523-018-0602-1.

51. Lee HJ, Seo JY, Ahn JH, et al. Tumor-associated lymphocytes predict response to neoadjuvant chemotherapy in breast cancer patients. J Breast Cancer. 2013;16(1):32-39. doi:10.4048/jbc.2013.16.1.32.

52. Dieci MV, Criscitiello C, Goubar A, et al. Prognostic value of tumor-infiltrating lymphocytes on residual disease after primary chemotherapy for triplenegative breast cancer: a retrospective multicenter study [published correction appears in Ann Oncol. 2015 Jul;26(7):1518]. Ann Oncol. 2014;25(3):611618. doi:10.1093/annonc/mdt556.

53. de Groot AF, Blok EJ, Charehbili A, et al. Strong CD8+ lymphocyte infiltration in combination with expression of HLA class I is associated with better tumor control in breast cancer patients treated with neoadjuvant chemotherapy. Breast Cancer Res Treat. 2019;175(3):605-615. doi:10.1007/s10549-019-05195y.

54. Issa-Nummer Y, Darb-Esfahani S, Loibl S, et al. (2013) Prospective validation of immunological infiltrate for prediction of response to neoadjuvant chemotherapy in HER2-negative breast cancer-a substudy of the neoadjuvant GeparQuinto trial. PloS One 8(12): e79775.

doi:10.1371/journal.pone.0079775.

55. Ali HR, Chlon L, Pharoah PD, et al. Patterns of immune infiltration in breast cancer and their clinical implications: a gene-expression-based retrospective study. PLoS Med 2016;13:e1002194. doi:10.1371/journal.pmed.1002194.

56. Mahmoud SM, Paish EC, Powe DG, et al. Tumor-infiltrating CD8+ lymphocytes predict clinical outcome in breast cancer. J Clin Oncol. 2011;29(15):19491955. doi:10.1200/JCO.2010.30.5037.

57. Miyashita M, Sasano H, Tamaki K, et al. Prognostic significance of tumor-infiltrating CD8+ and FoxP3+ lymphocytes in residual tumors and alterations in these parameters after neoadjuvant chemotherapy in triple-negative breast cancer: a retrospective multicenter study. Breast Cancer Res 2015;17:124. doi:10.1186/s13058-015-0632-x.

58. Jiang D, Gao Z, Cai Z, et al. Clinicopathological and prognostic significance of FOXP3+ tumor infiltrating lymphocytes in patients with breast cancer: a meta-analysis. BMC Cancer 2015;15:727. doi:10.1186/s12885-015-1742-7. 
59. Demaria S, M.D. Volm, R.L. Shapiro, et al., Development of tumor-infiltrating lymphocytes in breast cancer after neoadjuvant paclitaxel chemotherapy. Clin Cancer Res, 2001. 7(10): p. 3025-3030.

60. Ladoire S, L.Arnould, L Apetoh, et al., Pathologic complete response to neoadjuvant chemotherapy of breast carcinoma is associated with the disappearance of tumor-infiltrating foxp3+ regulatory T cells. Clin Cancer Res, 2008. 14(8): p. 2413-20. doi:10.1158/1078-0432.CCR-07-4491.

61. Lee HJ, Lee JJ, Song IH, et al. Prognostic and predictive value of Nano String-based immune-related gene signatures in a neoadjuvant setting of triplenegative breast cancer: relationship to tumor-infiltrating lymphocytes. Breast Cancer Res Treat. 2015;151:619-27. doi:10.1007/s10549-015-3438-8

62. Gu-Trantien C, Loi S, Garaud S, et al. CD4(+) follicular helper T cell infiltration predicts breast cancer survival. J Clin Invest. 2013;123:2873-92. doi:10.1172/JCl67428.

\section{Tables}


Table 1

Characteristics of the included studies

\begin{tabular}{|c|c|c|c|c|c|c|c|c|c|c|}
\hline $\begin{array}{l}\text { Authors and } \\
\text { published } \\
\text { years }\end{array}$ & $\begin{array}{l}\text { Data } \\
\text { collection }\end{array}$ & $\begin{array}{l}\text { Type of } \\
\text { lymphocytes }\end{array}$ & $\begin{array}{l}\text { Number of } \\
\text { participant }\end{array}$ & $\begin{array}{l}\text { Country of } \\
\text { origin }\end{array}$ & $\begin{array}{l}\text { Duration } \\
\text { of } \\
\text { follow- } \\
\text { up } \\
\text { (months) }\end{array}$ & $\begin{array}{l}\text { Clinicopathologic } \\
\text { characteristic }\end{array}$ & $\begin{array}{l}\text { Cut- } \\
\text { off } \\
\text { value }\end{array}$ & $\begin{array}{l}\text { Short- } \\
\text { term } \\
\text { prognosis }\end{array}$ & $\begin{array}{l}\text { Long- } \\
\text { term } \\
\text { prognosis }\end{array}$ & $\begin{array}{l}\text { Quality } \\
\text { score }\end{array}$ \\
\hline $\begin{array}{l}\text { Carsten } \\
\text { Denkert } \\
2010[35]\end{array}$ & Prospective & Total types & 1058 & Germany & - & HER2"ER & $60 \%$ & PCR & - & - \\
\hline $\begin{array}{l}\text { S. Loil } \\
2014[36]\end{array}$ & Prospective & Total types & 1010 & Australia & 62 & G $\square \mathrm{HR} \square \mathrm{HER} 2 \square \mathrm{Ki} 67$ & $50 \%$ & - & OSIDFS & - \\
\hline $\begin{array}{l}\text { Roberto } \\
\text { Salgado, MD } \\
2015[37]\end{array}$ & Prospective & Total types & 455 & - & 50.64 & $\mathrm{~N} \square \mathrm{T}$ 口HER2 & $\begin{array}{l}10 \% \\
\text { INC }\end{array}$ & PCR & DFS & - \\
\hline $\begin{array}{l}\text { M. V. Dieci1 } \\
2016[38]\end{array}$ & Prospective & Total types & 121 & Italy & - & GıERロHER2ロKi67 & $60 \%$ & PCR & OSIDFS & - \\
\hline $\begin{array}{l}\text { Michail } \\
\text { lgnatiadis } \\
2018[41]\end{array}$ & Prospective & Total types & 225 & Belgium & 56.4 & GロHER2 & $60 \%$ & PCR & DFS & - \\
\hline $\begin{array}{l}\text { Marcus } \\
\text { Schmidt } \\
2018[42]\end{array}$ & Prospective & $\begin{array}{l}\mathrm{CD}^{+} \square \\
\text { Foxp3 }{ }^{+} \square \\
\text { CXCL13 }\end{array}$ & 1010 & Australia & 62 & $\begin{array}{l}\mathrm{T} \square \mathrm{N} \square \mathrm{G} \square \mathrm{HR} \square \mathrm{HER} 2 \square \\
\mathrm{Ki} 67\end{array}$ & $50 \%$ & - & DFS & - \\
\hline $\begin{array}{l}\text { Sibylle Loibl } \\
\text { 2017[40] }\end{array}$ & Prospective & Total types & 50 & Multicentre & - & $\begin{array}{l}\text { TロN口ER } \square \text { HER2 } \\
\text { Ki67 }\end{array}$ & $\begin{array}{l}10 \% \\
\text { INC }\end{array}$ & PCR & - & - \\
\hline $\begin{array}{l}\text { Carsten } \\
\text { Denkert } \\
2014[43]\end{array}$ & Prospective & Total types & 580 & Germany & - & $\mathrm{T} \square \mathrm{N} \square \mathrm{G} \square \mathrm{HR} \square \mathrm{HER} 2$ & $60 \%$ & PCR & - & - \\
\hline $\begin{array}{l}\text { IssaNummer } \\
2014[56]\end{array}$ & Prospective & Total types & 313 & Germany & - & $\mathrm{T} \square \mathrm{G} \square \mathrm{N} \square \mathrm{ER} \square \mathrm{HER} 2$ & $60 \%$ & PCR & - & - \\
\hline $\begin{array}{l}\text { Tomohiro } \\
\text { Ochi } \\
2019[45]\end{array}$ & Retrospective & Total types & 209 & Japan & 120 & $\mathrm{~T} \square \mathrm{N} \square \mathrm{ER} \square \mathrm{HER} 2$ & $10 \%$ & PCR & DFS & 8 \\
\hline $\begin{array}{l}\text { Hee Jin Lee } \\
2013[53]\end{array}$ & Retrospective & $\begin{array}{l}\text { CD8 }^{+} \square \\
\text { Foxp3 }^{+}\end{array}$ & 175 & Korea & - & - & $\begin{array}{l}40 \% \rrbracket \\
70 \%\end{array}$ & $\mathrm{RCR}$ & - & 6 \\
\hline $\begin{array}{l}\text { M. V. Dieci1 } \\
\text { 2014[54] }\end{array}$ & Retrospective & Total types & 278 & France & 76 & $\mathrm{G} \square \mathrm{T} \square \mathrm{N}$ & $60 \%$ & - & OSIDFS & 8 \\
\hline $\begin{array}{l}\text { Leonardo } \\
\text { Russo } \\
2019[50]\end{array}$ & Retrospective & Total types & 187 & Venezuela & 62.5 & GロHER2 & $30 \%$ & PCR & OS & 8 \\
\hline $\begin{array}{l}\text { YUKA ASANO } \\
2018[49]\end{array}$ & Retrospective & Total types & 177 & Japan & 3.4 & $\mathrm{G} \square \mathrm{T} \square \mathrm{N} \square \mathrm{Ki670PD-1}$ & $10 \%$ & PCR & OSIDFS & 8 \\
\hline $\begin{array}{l}\text { In Hye Song, } \\
\text { MD 2017[46] }\end{array}$ & Retrospective & $\begin{array}{l}\mathrm{CD}^{+} \\
\mathrm{CXCL} 13\end{array}$ & 108 & Korea & 34.9 & $\mathrm{G} \square \mathrm{T} \square \mathrm{N} \square \mathrm{PD}-1$ & $\begin{array}{l}10 \% \\
\text { INC }\end{array}$ & PCR & DFS & 6 \\
\hline $\begin{array}{l}\text { Bruna } \\
\text { Cerbelli } \\
2017[47]\end{array}$ & Retrospective & Total types & 54 & Italy & - & $\mathrm{G} \square \mathrm{T} \square \mathrm{N} \square \mathrm{Ki670PD-1}$ & $50 \%$ & PCR & - & 8 \\
\hline $\begin{array}{l}\text { Thaer Khoury, } \\
\text { M D 2017[48] }\end{array}$ & Retrospective & Total types & 331 & Canadian & - & $\mathrm{T} \square \mathrm{N} \square \mathrm{G} \square \mathrm{ER} \square \mathrm{HER} 2$ & $\begin{array}{l}10 \% \\
\text { INC }\end{array}$ & PCR & - & 6 \\
\hline
\end{tabular}

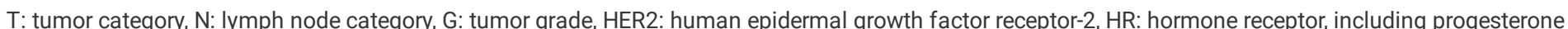

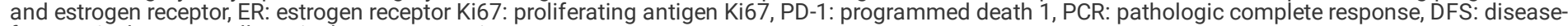
free survival, OS: overall survival, INC: per 10\% increment. 


\begin{tabular}{|c|c|c|c|c|c|c|c|c|c|c|}
\hline $\begin{array}{l}\text { Authors and } \\
\text { published } \\
\text { years }\end{array}$ & $\begin{array}{l}\text { Data } \\
\text { collection }\end{array}$ & $\begin{array}{l}\text { Type of } \\
\text { lymphocytes }\end{array}$ & $\begin{array}{l}\text { Number of } \\
\text { participant }\end{array}$ & $\begin{array}{l}\text { Country of } \\
\text { origin }\end{array}$ & $\begin{array}{l}\text { Duration } \\
\text { of } \\
\text { follow- } \\
\text { up } \\
\text { (months) }\end{array}$ & $\begin{array}{l}\text { Clinicopathologic } \\
\text { characteristic }\end{array}$ & $\begin{array}{l}\text { Cut- } \\
\text { off } \\
\text { value }\end{array}$ & $\begin{array}{l}\text { Short- } \\
\text { term } \\
\text { prognosis }\end{array}$ & $\begin{array}{l}\text { Long- } \\
\text { term } \\
\text { prognosis }\end{array}$ & $\begin{array}{l}\text { Quality } \\
\text { score }\end{array}$ \\
\hline $\begin{array}{l}\text { Xia Yang } \\
2018[52]\end{array}$ & Retrospective & Total types & 143 & China & 53 & $\begin{array}{l}\mathrm{T} \square \mathrm{N} \square \mathrm{G} \square \mathrm{HER} 2 \square \\
\mathrm{Ki} 67\end{array}$ & $\begin{array}{l}10 \% \\
\text { INC }\end{array}$ & PCR & OSIDFS & 8 \\
\hline $\begin{array}{l}\text { A. F. de Grootl } \\
2019[55]\end{array}$ & Retrospective & $\begin{array}{l}\text { CD }^{+} \square \\
\text { Foxp3 }^{+}\end{array}$ & 196 & Netherlands & 55.2 & HER2 & - & PCR & DFS & 6 \\
\hline
\end{tabular}

T: tumor category, N: lymph node category, G: tumor grade, HER2: human epidermal growth factor receptor-2, HR: hormone receptor, including progesterone and estrogen receptor, ER: estrogen receptor Ki67: proliferating antigen Ki67, PD-1: programmed death 1, PCR: pathologic complete response, DFS: diseasefree survival, OS: overall survival, INC: per 10\% increment.

Table 2

Association between TILs and breast cancer clinicopathological feature

\begin{tabular}{|c|c|c|c|c|c|c|}
\hline \multirow[t]{2}{*}{ Subgroup } & \multicolumn{3}{|c|}{ PCR囚per $10 \%$ increment $\rrbracket$} & \multicolumn{3}{|c|}{ DFS $₫$ per $10 \%$ increment $囚$} \\
\hline & $\mathrm{HR} \rrbracket 95 \% \mathrm{Cl} \rrbracket$ & $P$-value & $2 \otimes \% \bigotimes$ & $\mathrm{HR} \rrbracket 95 \% \mathrm{Cl} \rrbracket$ & $P$-value & $R \otimes \% \bigotimes$ \\
\hline $\begin{array}{l}\text { Age: } \leq 50 \text { vs } \\
\varangle 50 \text { years }\end{array}$ & $1.14 \llbracket 0.66,1.99 \rrbracket$ & 0.640 & 51.0 & $0.76 \rrbracket 0.43,1.35 \rrbracket$ & 0.350 & 59.0 \\
\hline Tumor grade (G3 vs G1-2) & $1.21 ه 0.93,1.58 \rrbracket$ & 0.150 & 0.0 & $0.95 \rrbracket 0.64,1.42 \rrbracket$ & 0.800 & 0.0 \\
\hline Lymph node status (- vs +) & $1.44 \llbracket 0.96,2.17 \rrbracket$ & 0.080 & 9.0 & - & - & - \\
\hline Lymph node status (+ vs -) & - & - & - & $3.34 \rrbracket 2.28,4.89 \rrbracket$ & $₫ 0.00001 *$ & 29.0 \\
\hline $\begin{array}{l}\text { Tumor size } \\
\text { (T2 vs T1) }\end{array}$ & - & - & - & $1.34 \llbracket 0.93,1.91 \rrbracket$ & 0.110 & 0.0 \\
\hline
\end{tabular}

\section{Figures}



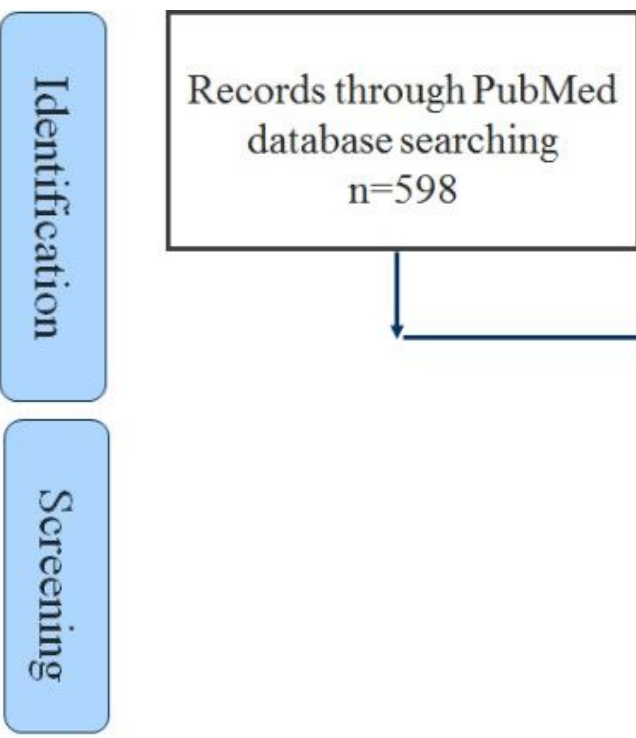

Records through EMBASE
database searching

$$
\mathrm{n}=120
$$
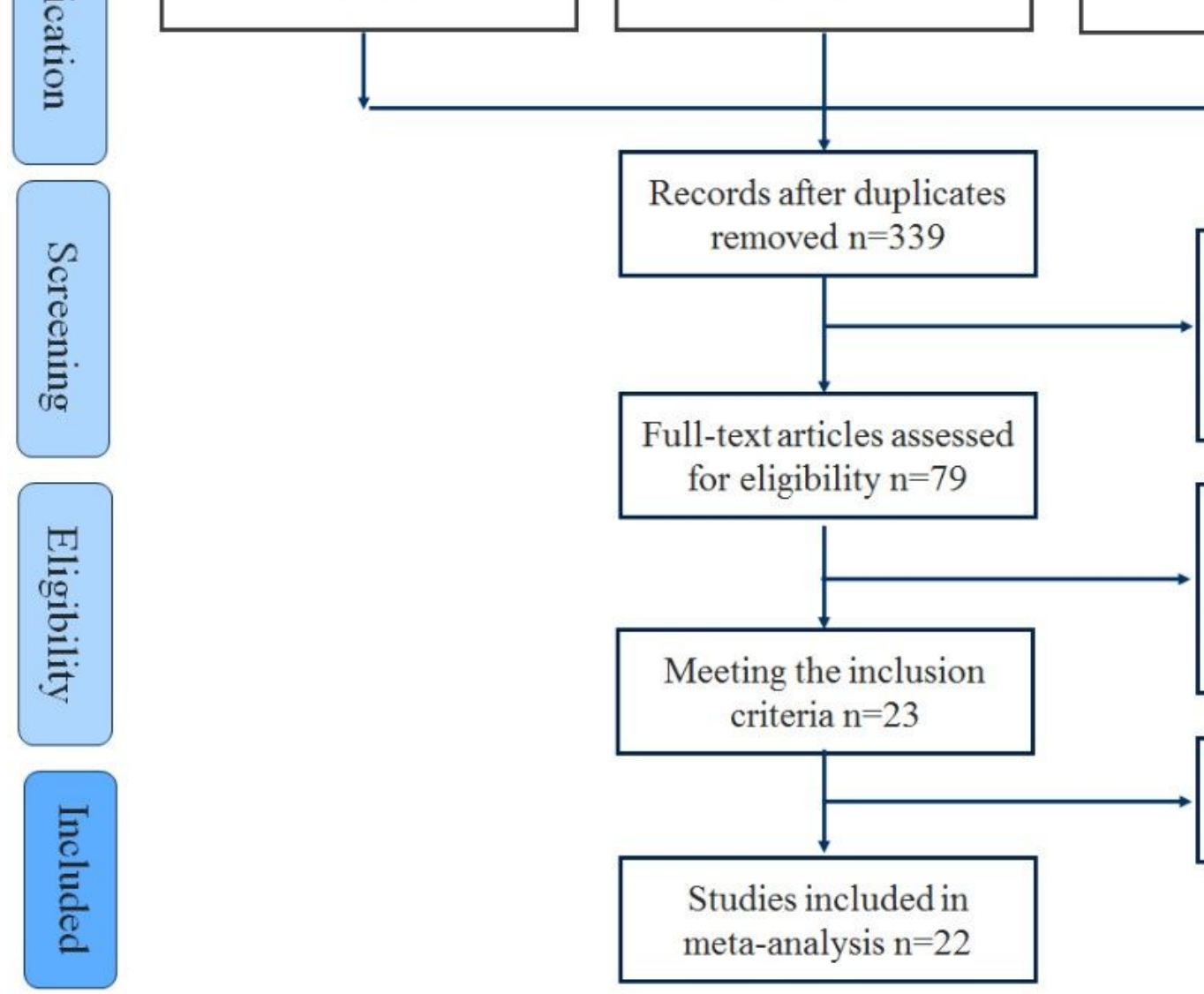

Meeting the inclusion criteria $n=23$

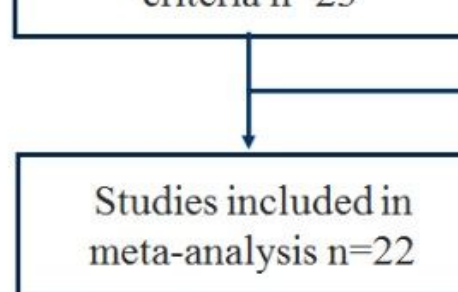

79 abstracts excluded

26 title excluded

127 not meting criteria

28 without full-text

18 no outcome indicator

11data missing

2 non-English

25 vaguely defined for TIL

\section{Figure 1}

Flowchart of the selection of studies for inclusion in the meta-analysis. 

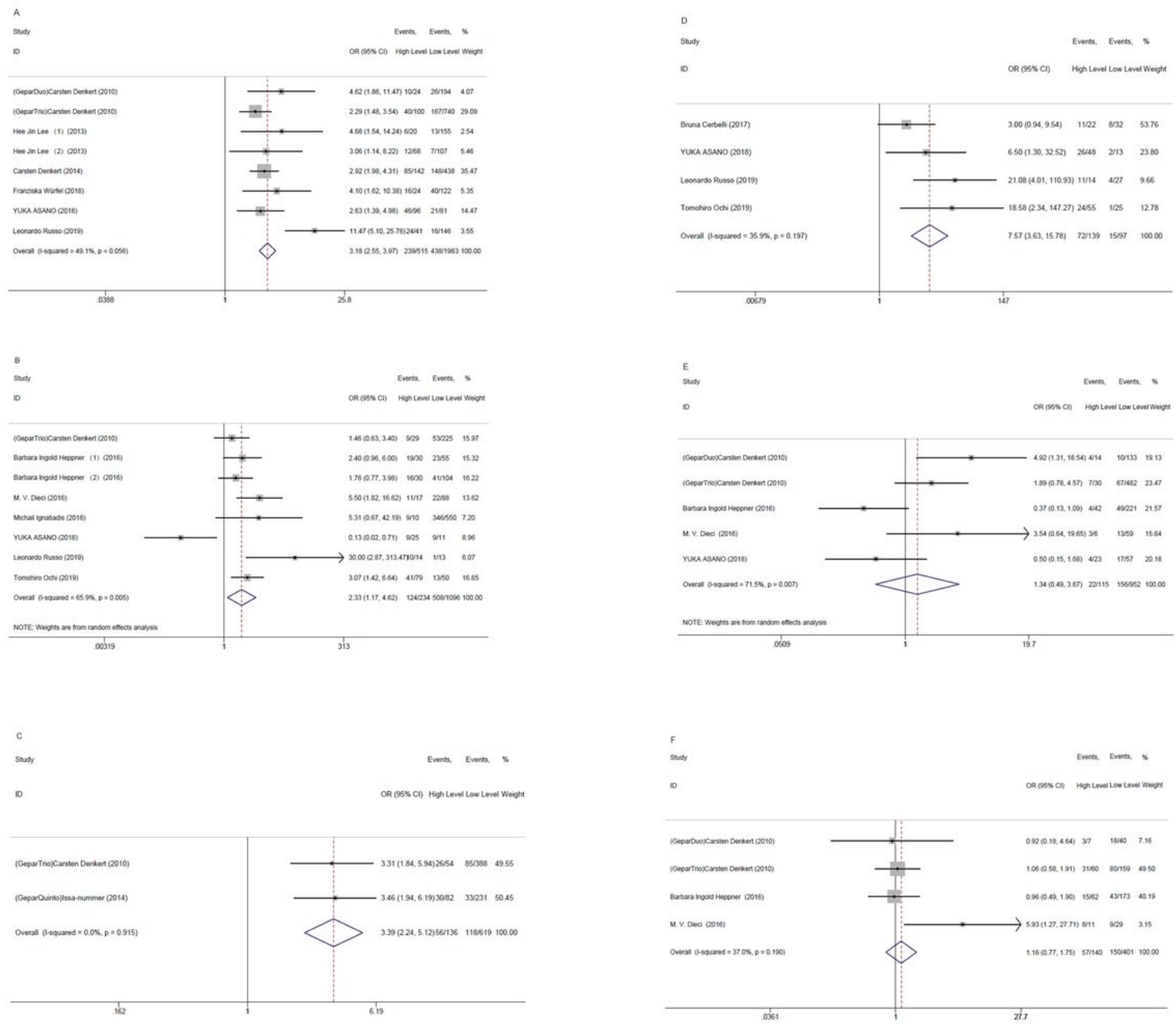

\section{Figure 2}

The forest plot of ORs was assessed for association between TILs and breast cancer short-term outcome (neoadjuvant chemotherapy PCR rate). A: total TILS and all breast cancer; B: TILs and HER-2 positive breast cancer; C: TILs and HER-2 negative breast cancer; D: TILs and Triple negative breast cancer; E: TILs and ER positive breast cancer; F: TILs and ER negative breast cancer.
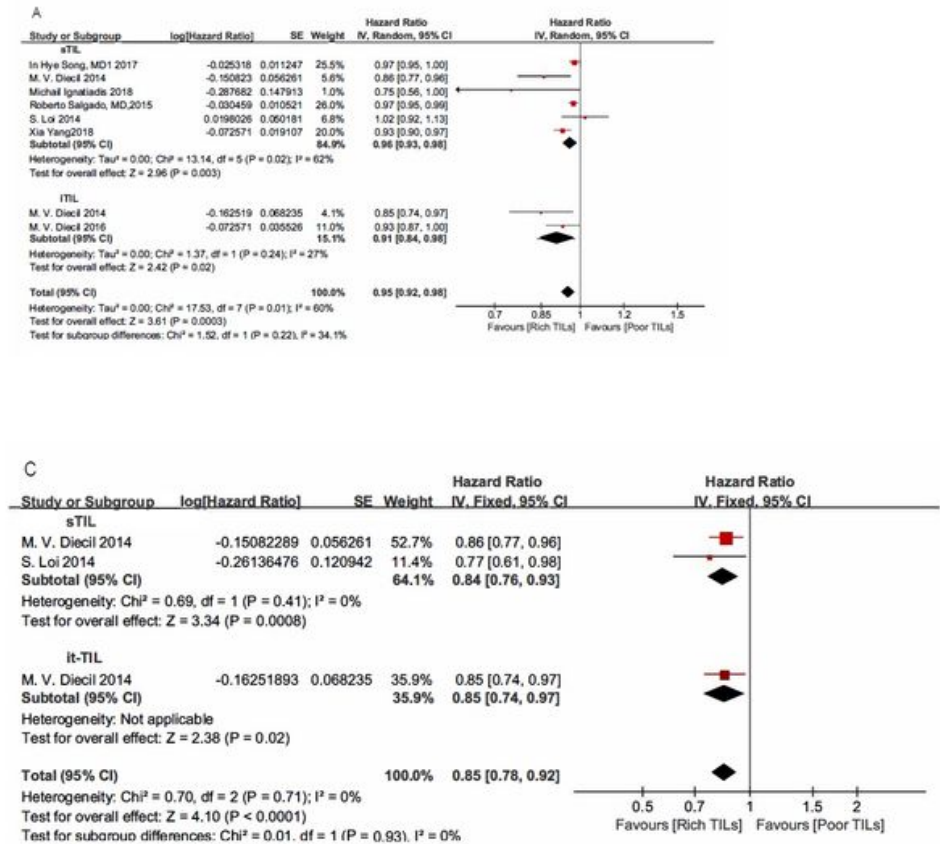

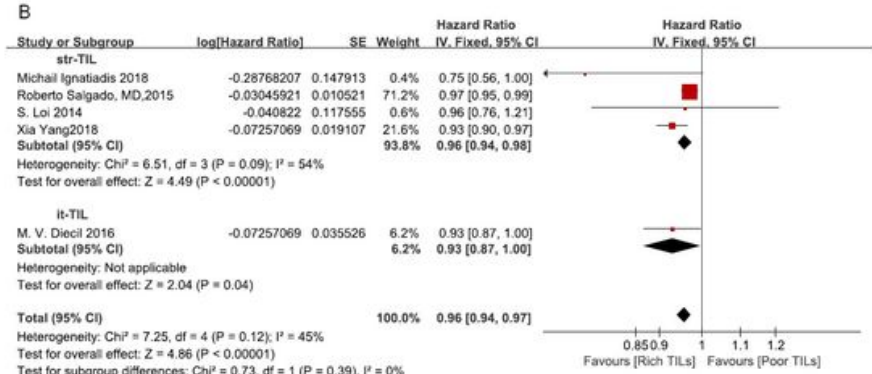

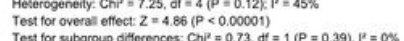


Figure 3

The forest plot of HRs was assessed for association between TILs and its subtypes and breast cancer disease-free survival. A: total TILs and all breast cancer; B: TILs and HER-2 positive breast cancer; C: TILs and Triple negative breast cancer.
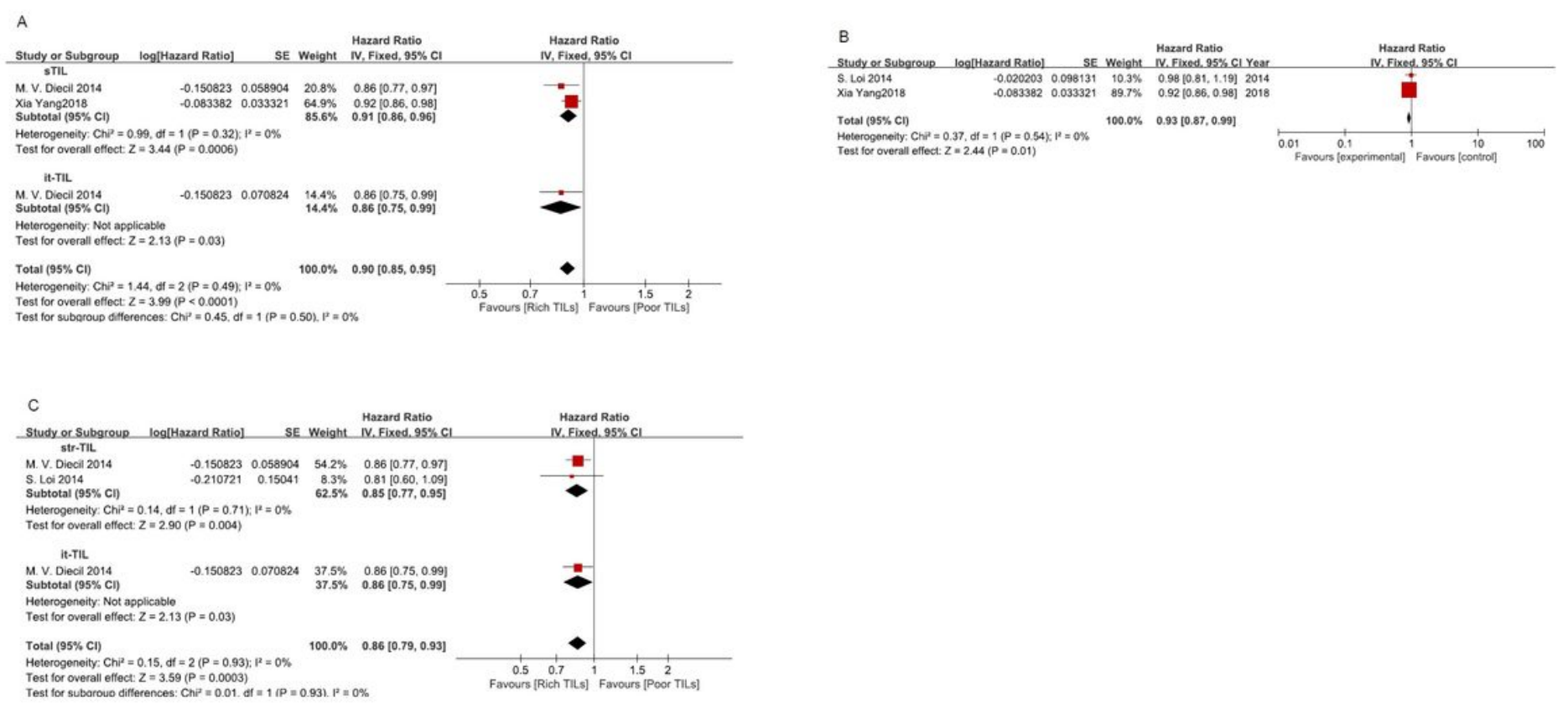

\section{Figure 4}

The forest plot of HRs was assessed for association between total TILs and breast cancer overall survival prognosis. A: total TILs and all breast cancer; B: TILs and HER-2 positive breast cancer; C: TILs and Triple negative breast cancer.

\section{Supplementary Files}

This is a list of supplementary files associated with this preprint. Click to download.

- Additionalfile1.docx 